Cristina Cabada Giadás

\title{
Iluminacións medievais na rede: retos e oportunidades para a investigación Medieval illuminations on the internet: Challenges and opportunities for research
}

Resumo: Procurar miniaturas que respondan a un criterio específico nos recursos dispoñibles en Internet entraña dificultades cando se pretende unha recuperación exhaustiva, particularmente cando as buscas se centran en códices dos que conservamos un gran número, como os libros de horas. Localizar eficazmente iluminacións require un coñecemento previo do funcionamento de certos recursos, entre os que salientan as bases de datos de imaxes. A partir dun caso práctico de busca nestas ferramentas, o presente traballo quere dar conta dalgunhas particularidades que poden influír na recuperación. Posto que a localización de ilustracións pertinentes esixe completar a procura nos manuscritos accesibles nas coleccións dixitais, e tendo en conta a dedicación que requiren estas tarefas, considérase así mesmo a oportunidade da elaboración de instrumentos de carácter monográfico que poidan servir de ponte entre quen investiga e o abundante caudal de imaxes ao seu dispor.

Palabras clave: Bases de datos de imaxes; indexación de imaxes; recuperación de imaxes; iluminación de manuscritos; libros de horas.

Abstract: Searching Internet resources for manuscript illuminations conforming to a specific criterion can be a difficult undertaking when exhaustiveness is the aim, and especially when the search is conducted on manuscripts which are available in large numbers, such as the books of hours. Effective retrieval requires prior knowledge of certain search tools, particularly those associated with image databases. Through the analysis of a specific query when using such resources, the present study aims to identify a number of key characteristics of image retrieval here. Since finding appropriate images also entails consulting

\footnotetext{
Nota: Quixera expresar o meu agradecemento a Rocío Sánchez Ameijeiras, a Ana González da Costa e ás persoas que revisaron anonimamente a versión previa desta contribución polas súas enriquecedoras achegas.
}

Cristina Cabada Giadás, Biblioteca Universitaria de Santiago de Compostela

Ә Open Access. ( 2019 Cristina Cabada Giadás, published by de Gruyter. (c) BY-NC-ND This work is licensed under the Creative Commons Attribution-NonCommercial-NoDerivatives 4.0 License. https://doi.org/10.1515/9783110585421-003 
accessible digitized manuscripts, and also bearing in mind the amount of time necessary to carry out these tasks, we suggest that it might be useful to develop resources focused on a topic, with this serving as a bridge between researchers and the overwhelming volume of images available.

Keywords: Image Databases; Image Indexing; Image Retrieval; Manuscript Illumination; Books of Hours.

\section{Introdución}

Na súa reflexión sobre a relación entre a Historia da Arte e as prácticas dixitais, Johanna Drucker quixo deixar clara a distinción entre o que ela denominou “digitized art history”, caracterizada polo uso instrumental por parte dos investigadores dos recursos electrónicos en liña, e a "digital art history", que supón o emprego na investigación de técnicas de análise baseadas na tecnoloxía computacional e cuxos resultados son susceptibles de transformar os modos de pensar os obxectos artísticos (Drucker 2013). A procura de novos modelos interpretativos e novos paradigmas de coñecemento como resultado da converxencia entre as ciencias da computación, os medios dixitais e a cultura artística constitúe tamén a clave da definición de Historia da Arte Dixital para Nuria Rodríguez, que ve nesta orientación da disciplina a xustificación da súa inclusión no eido das Humanidades Dixitais (Rodríguez Ortega 2013).

A profusión de materiais accesibles en liña no campo das artes visuais e o patrimonio cultural está na base de iniciativas e proxectos que camiñan neste sentido e que se inscriben, polo tanto, no ámbito da Historia da Arte Dixital, pero repercute -ou debería repercutir- igualmente nas prácticas tradicionais da investigación no eido histórico-artístico. Tamén aquí se presentan retos, e un deles é o da localización de documentación visual relevante para unha investigación no seo do inxente caudal de imaxes e información dispoñibles. $\mathrm{Na}$ era dixital, a accesibilidade estase a incrementar dun xeito particularmente significativo no ámbito da miniatura medieval, pois os manuscritos iluminados, que constituíron ata época relativamente recente un dos conxuntos de obras máis difíciles de consultar, son agora obxecto privilexiado das políticas de dixitalización. Hoxe podemos visualizar ilustracións dun número cada vez maior de códices, moitos deles de menor mérito artístico que os que concitaron fundamentalmente o interese dos especialistas no pasado, pero non por iso exentos de valor desde o punto de vista documental. Entre outros aspectos, as iluminacións accesibles na rede revelan a súa utilidade á hora de analizar o contexto de manuscritos determinados, facilitando o descubrimento de 
referentes estilísticos ou iconográficos e, como consecuencia, labores como a datación e a determinación de autorías. Para o estudo dun tema ou motivo iconográfico medieval, baseado na constitución dun corpus necesariamente extenso (Baschet/Rigaux 2007), as iluminacións dispoñibles en liña constitúen un material imprescindible.

Localizar imaxes para documentar un traballo de investigación pode resultar, en certos casos e dependendo do obxecto de estudo, unha tarefa complexa, particularmente cando se pretende unha recuperación exhaustiva. Resulta necesario, polo tanto, coñecer os recursos e as súas características, porque estas determinan, en boa medida, a obtención de resultados.

Os instrumentos máis solventes de que dispoñemos na actualidade para localizar miniaturas medievais na rede son, por un lado, as bases de datos de imaxes e recursos de similar natureza, que permiten recuperar as ilustracións a partir de información asociada ás mesmas; por outro lado contamos coas coleccións ou bibliotecas dixitais, a través das cales as institucións facilitan a consulta dos facsímiles dixitais dos seus manuscritos. Nas bases de datos de imaxes, os metadatos vinculados a cada ilustración axilizan substancialmente a súa recuperación. A localización de miniaturas nos facsímiles das coleccións dixitais, en troques, implica unha busca manual en cada manuscrito, que require maior inversión de tempo. Esta operación, con todo, presenta menor risco de erro, xa que a localización das imaxes nos códices dixitalizados non pasa por un proceso de interrogación como o que demandan as bases de datos iconográficas. Nestas últimas, unha estratexia de busca que non estea ben formulada ou o descoñecemento das características intrínsecas de cada ferramenta poden conducir a resultados equivocados.

As consultas que temos realizado en bases de datos de iluminacións de manuscritos co obxecto de levar a cabo unha procura exhaustiva -a localización das ilustracións do texto dos salmos penitenciais en libros de horas- permitíronnos percibir peculiaridades nestas ferramentas susceptibles de afectar dun modo ou doutro á recuperación. No proceso descartamos a interrogación aos metadatos asociados ás imaxes (que é para o que estes recursos están concibidos) e optamos pola busca de todos os libros de horas e, a continuación, localizando manualmente a ilustración dos salmos penitenciais entre as miniaturas indexadas de cada manuscrito. Os datos que ofrecemos nas páxinas que seguen proveñen do exame das descricións de ilustracións de 710 códices. A estratexia empregada permitiunos detectar casos nos que se producirían perdas de información derivadas da interrogación a determinados metadatos. Desta cuestión procuramos dar conta a seguir, na medida en que poida axudar a evitar desacertos nas buscas e a sacar mellor partido destas ferramentas. Non abordaremos aquí, non obstante, a análise dos recursos nin das causas que determinan o seu rendemento, algo que 
ten que ver coa súa natureza e coa historia da súa xénese e desenvolvemento, e que merecería un estudo específico. ${ }^{1}$

No presente traballo referirémonos aos instrumentos que a continuación se relacionan, que constitúen unha selección entre os máis relevantes en acceso libre onde se describen miniaturas: ${ }^{2}$

- Mandragore (http://mandragore.bnf.fr/html/accueil.html, consultado 10/01/ 2018). Base de datos iconográfica da Bibliothèque Nationale de France con imaxes indexadas dos seus manuscritos.

- British Library Catalogue of Illuminated Manuscripts (en diante, BLCIM) (https://www.bl.uk/catalogues/illuminatedmanuscripts/welcome.htm, consultado 10/01/2018). Base de datos onde se describen miniaturas de manuscritos da British Library. Dalgúns deles só se ofrece unha selección de ilustracións.

- Enluminures (http://www.enluminures.culture.fr/documentation/enlumine/ fr/, consultado 10/01/2018). Proxecto conxunto do Service du livre et de la lecture e do Institut de recherche et d'histoire des textes (IRHT) no que se describen miniaturas de bibliotecas municipais francesas. ${ }^{3}$

- Medieval and Renaissance Manuscripts, Morgan Library \& Museum (en diante, Corsair). Recolle a descrición das ilustracións dos manuscritos desta institución. Os rexistros iconográficos intégranse no catálogo da biblioteca, denominado Corsair (http://corsair.themorgan.org/, consultado 10/01/2018). Diferentes opcións de consulta e visualización de resultados son posibles a través de http://ica.themorgan.org/search/search.asp (consultado10/01/2018).

- Digital Scriptorium (http://bancroft.berkeley.edu/digitalscriptorium/, consultado 10/01/2018). Portal do que é responsable un consorcio de bibliotecas e

1 Por falta de espazo, non se tratan tampouco cuestións relativas ás particularidades das sintaxes de busca en cada recurso, cuxo coñecemento resulta tamén imprescindible para evitar desacertos na recuperación.

2 Exclúense da selección, polo tanto, recursos significativos pero só consultables mediante subscrición, como The Index of Medieval Art ou ARTstor. Para máis información sobre estas e outras bases de datos de imaxes artísticas véxase Soler i Fabregat (2003) e Baschet e Dittmar (2015: 38-42). O portal Ménestrel ofrece unha lista exhaustiva de bases de datos de iluminacións: http://www.menestrel.fr/spip.php?rubrique602, consultado 10/01/2018).

3 Os rexistros de Enluminures consúltanse tamén a través de Initiale (http://initiale.irht.cnrs. $\mathrm{fr} /$, consultado 10/02/2018), a base de datos de manuscritos iluminados das bibliotecas públicas francesas da que provén Enluminures (Lalou 2001). En Initiale os datos revísanse permanentemente, polo que algúns rexistros de Enluminures aparecen alí enriquecidos, e certas características desta última base de datos, melloradas. Initiale acaba de presentar unha nova versión a principios do ano 2018 que optimiza substancialmente as opcións de busca (https://irht. hypotheses.org/3388, consultado 10/02/2018). 
museos norteamericanos e que integra un catálogo colectivo de manuscritos con imaxes dalgúns deles sucintamente descritas. De moitos manuscritos só se presenta unha pequena selección das miniaturas.

- Medieval Illuminated Manuscripts (http://manuscripts.kb.nl/, consultado 10/01/2018). Denominación da versión en inglés da base de datos holandesa que indexa miniaturas da Koninklijke Bibliotheek e do Museum MeermannoWestreenianum.

- LUNA (http://bodley30.bodley.ox.ac.uk:8180/luna/servlet, consultado 10/01/ 2018). Base de imaxes froito da colaboración entre ARTstor e a Bodleian Library de Oxford que ofrece a descrición de miniaturas procedentes da dixitalización do fondo de diapositivas desta biblioteca.

\section{Recuperación nas bases de datos de imaxes}

Varios aspectos relativos ao tratamento documental das páxinas miniadas inciden de forma significativa, ao noso ver, na consecución dos resultados nestas ferramentas. Un deles é a forma en que se aborda a descrición de cada ilustración e de todas as escenas, motivos ou figuras contidas nela. Resultan determinantes, así mesmo, a riqueza dos metadatos dos recursos e o nivel de coherencia na catalogación das miniaturas.

\subsection{Descrición da trama das ilustracións}

Como é sabido, as ilustracións de manuscritos medievais constitúen unidades complexas que abranguen combinacións de imaxes repartidas en diferentes ámbitos da páxina ou da dobre páxina (miniatura principal, iniciais, marxes, viñetas, medallóns). Considerar a rede de vínculos que se establece entre elas resulta imprescindible para descifrar os matices de significado da iluminación.

Nalgúns recursos, pasando por alto este aspecto, optouse en moitas ocasións por fragmentar a descrición das páxinas, dedicando diferentes rexistros iconográficos a cada unha das escenas que as compoñen, separando o que os artífices concibiron como un todo. Nestes casos, resulta difícil localizar a concorrencia de escenas ou motivos relacionados entre si ou con algún elemento secundario. Posto que as ecuacións de busca se aplican sobre cada rexistro, para acadar esta información non basta a interrogación, que debe complementarse cunha busca manual. Así, tomando como exemplo a estampa máis común dos salmos penitenciais nos libros de horas -o Rei David orando, en actitude que se asocia co arrepentimento-debemos 
saber que se quixésemos localizar todas as ilustracións nas que a escena do Rei se combina coa da orixe do seu pecado (o Baño de Betsabé), en certas bases de datos deberemos solicitar, ou ben todas as de David naquela actitude, ou ben todas as do Baño de Betsabé - nunca ambas na mesma ecuación de busca-, e revisar todos os resultados para encontrar as coincidencias. Analizando a descrición das ilustracións dos salmos penitenciais, detectamos a descrición fragmentada das miniaturas en Mandragore (Figuras 2.1 e 2.2), Enluminures e Medieval Illuminated Manuscripts. En Digital Scriptorium, BLCIM, LUNA e Corsair, en troques, adóitanse describir xuntas todas as escenas e motivos dunha páxina. BLCIM, a base de datos da British Library, con todo, non o fai de xeito sistemático, o que produce tamén perdas de información cando se procura a concorrencia de motivos ou escenas nunha ilustración.

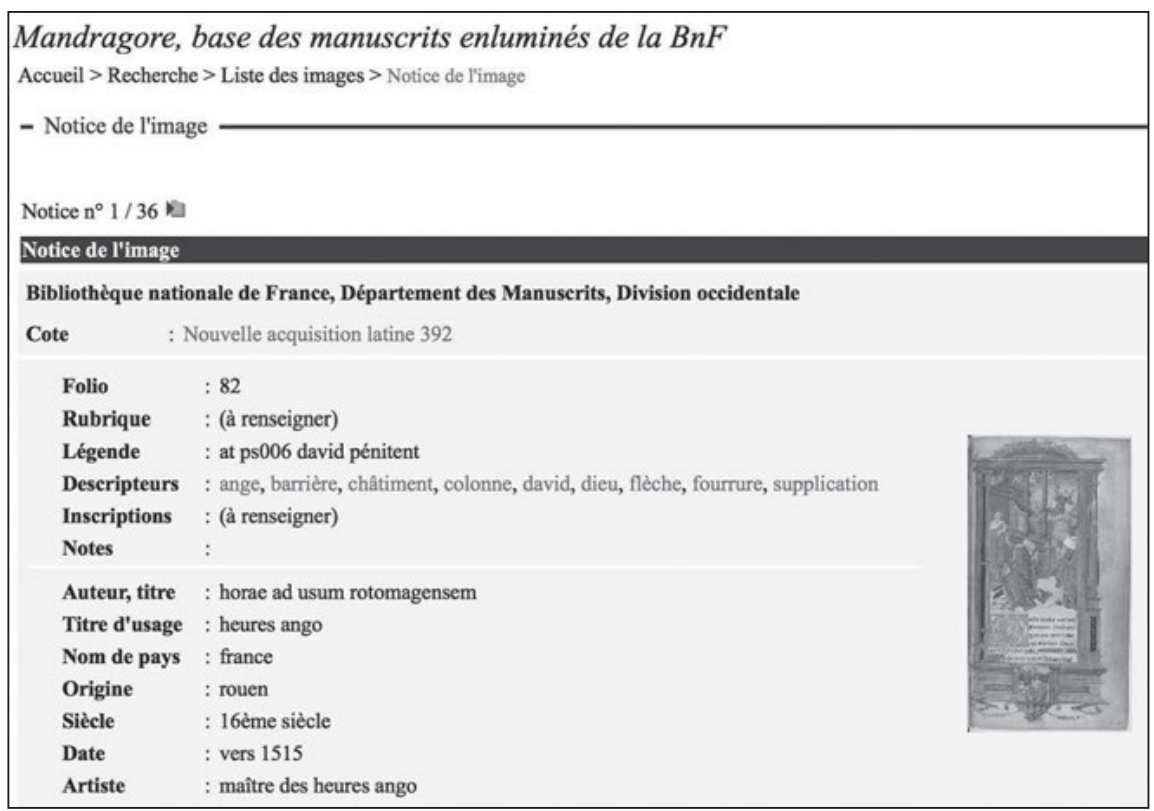

Figura 2.1: Rexistro iconográfico da escena de David arrepentido no f.82r das Heures Ango (Paris, BNF, NAL 392) (Fonte: Mandragore, consultado 10/01/2018).

Do exame dos resultados das buscas que realizamos concluímos, por outra parte, que as ferramentas examinadas non permiten normalmente a recuperación sistemática das ilustracións cando estas están distribuídas entre o verso dun folio e o recto do seguinte, ou ben cando existen vínculos entre elementos de ambas páxinas, en composicións concibidas tamén para ser vistas simultaneamente. Sirva de exemplo a ilustración dos salmos penitenciais nas Grandes Heures d’Anne de Bretagne (Paris, BNF, Latin 9474, f.91r-f.92v): alí, a imaxe 


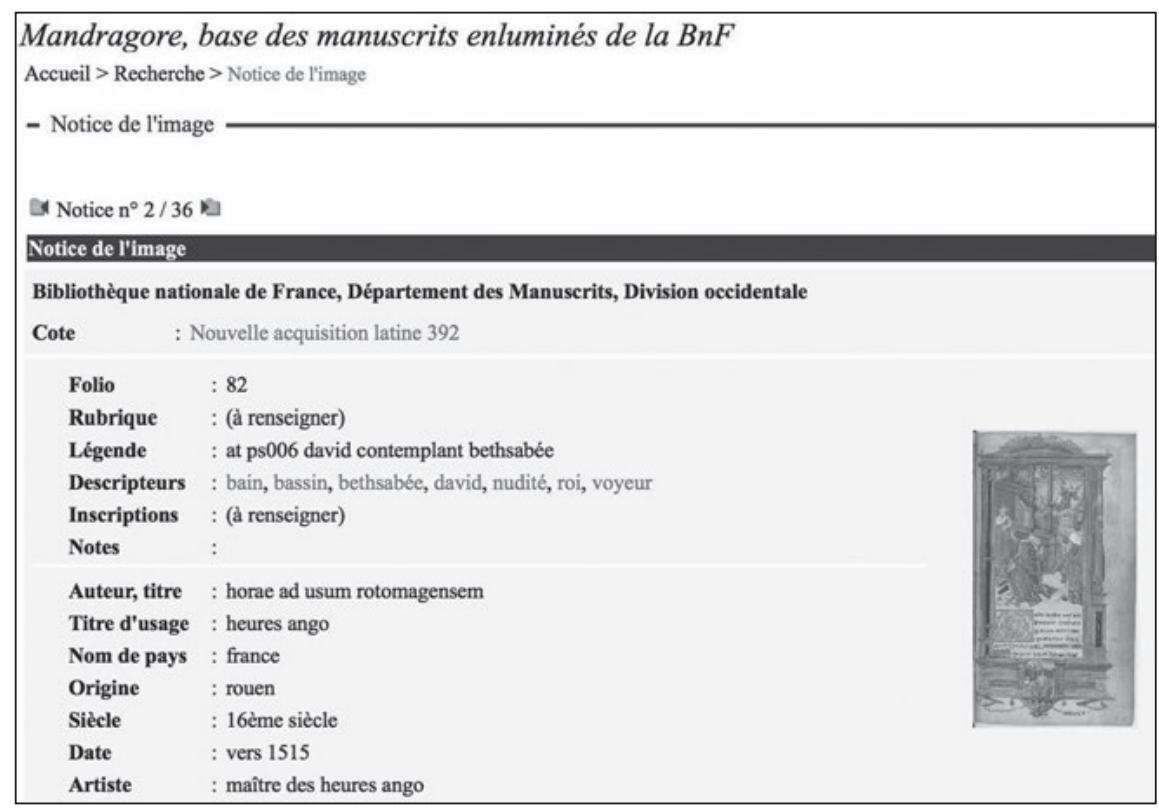

Figura 2.2: Rexistro iconográfico da escena do Baño de Betsabé no f.82r das Heures Ango (Paris, BNF, NAL 392) (Fonte: Mandragore, consultado 10/01/2018).

de David arrepentido vincúlase á do seu pecado encarnado nunha parella de simios en actitude cariñosa, situados na marxe inferior da páxina contigua á aquela onde aparece o Rei. ${ }^{4}$ A pesar de que ambas as imaxes están indexadas en Mandragore, a suxestiva combinación non se recuperaría a partir dunha busca nesta base de datos que procurase a asociación entre David e os monos. E nin sequera sairía á luz mediante a solución apuntada no parágrafo anterior -unha revisión manual de todos os resultados da busca de David penitente neste recurso- posto que a ilustración está repartida, non só en dous rexistros iconográficos distintos, senón tamén en dúas imaxes dixitais independentes. ${ }^{5}$

Hai que ter presente, polo tanto, as limitacións que os recursos ofrecen cando se intenta localizar exhaustivamente a representación conxunta de escenas ou motivos, estean estes repartidos en diferentes ámbitos dunha páxina ou entre as páxinas contiguas dun manuscrito.

4 Visualización en Gallica, f.91v-f.92r: http://gallica.bnf.fr/ark:/12148/btv1b550093038/f188. double (consultado 15/01/2018).

5 Rexistros en Mandragore: David no f.91v: http://mandragore.bnf.fr/ark:/12148/cgfbt68668n. Simios na marxe do f.92r: http://mandragore.bnf.fr/ark:/12148/cgfbt686690 (consultado 15/01/18). 


\subsection{Metadatos}

Desde o punto de vista da recuperación, parécennos especialmente relevantes, por un lado, os metadatos relativos á identificación do contido semántico das imaxes -a expresión verbal do tema ou temas representados e dos elementos que os compoñen $-^{6}$ e, polo outro, os metadatos que consignan o texto que aquelas ilustran nun códice determinado.

\subsubsection{Texto relacionado}

Comezando polo último aspecto citado, cabe sinalar as variantes do xeito de recollelo nos diferentes recursos, o que se traduce en máis ou menos posibilidades de localizar as miniaturas polo seu contexto textual.

Os rexistros de Corsair inclúen un campo de notas onde se explicita, de ser o caso, o texto litúrxico asociado á miniatura ("Liturgy") e outro campo ("Associated text") onde se consignan fragmentos relevantes como as inscricións ou as rúbricas. En Mandragore rexístrase ás veces o texto ilustrado no propio título da miniatura ("Légende") e dun xeito abreviado: así, a expresión "at ps006" (salmo 6) recupera a ilustración do íncipit dos salmos penitenciais. ${ }^{7}$ Mandragore conta tamén cun apartado para as inscricións e outro para as rúbricas (Figuras 2.1 e 2.2). Presentan un só campo para o texto asociado, e información máis sucinta polo tanto, a base holandesa Medieval Illuminated Manuscripts ("Accompanying text”) e Enluminures (“Contexte”) mentres que en LUNA e BLCIM especifícase nun apartado xenérico de descrición da imaxe. En Digital Scriptorium poucas veces se consigna este dato, e cando se fai é normalmente no título das miniaturas.

Para buscar ilustracións por texto asociado nun recurso cómpre saber, ademais, se aquel aparece recollido sistemática e univocamente. Nas descricións de miniaturas dos salmos penitenciais comprobamos que, salvo erros de catalogación puntuais, si se consigna, e dun xeito uniforme, en Mandragore,

6 Aínda que non tratamos aquí o concepto informático de "recuperación de imaxes baseada no contido" (CBIR, Content Based Image Retrieval), referido ao recoñecemento automático, cómpre sinalar que tamén para as imaxes medievais existe algún proxecto baseado neste modo de recuperación (Cayuela 2014: 24-25).

7 Noutras ocasións a información que ofrece Mandragore neste campo non designa o texto que acompaña a miniatura -que é ao que nos referimos aquí- senón o texto bíblico que a miniatura representa. 
Corsair, Medieval Illuminated Manuscripts e LUNA, así como en boa parte dos de BLCIM e Enluminures. Falta, como xa apuntamos, na maioría dos de Digital Scriptorium.

Apréciase, polo tanto, un rendemento bastante bo da maioría dos recursos considerados para a localización das ilustracións dos salmos penitenciais. Hai que ter en conta, non obstante, que non todos os textos reciben idéntica atención. Nos mesmos libros de horas temos constatado que, salvo Corsair e LUNA, os recursos apenas ofrecen esta información para outros textos devocionais que tamén integran este tipo de códices. Cómpre ter presente, polo tanto, que se o obxectivo é a recuperación rigorosamente exhaustiva da ilustración dun texto determinado, en certos casos e dependendo do texto de que se trate, na maioría das bases de datos resultará inevitable localizar primeiro todos os manuscritos susceptibles de contelo e facer, a continuación, unha busca manual.

\subsubsection{Descrición do contido}

O contido é, xunto coa autoría, un dos criterios máis empregados para a localización de imaxes artísticas nos recursos electrónicos (Hourihane 2002). Nalgunhas das ferramentas consideradas aquí emprégase linguaxe controlada para expresar esta información: en Mandragore utilízase un vocabulario propio (Angjeli/Isaac 2008); nos rexistros de Corsair, que están baseados nos do Index of Medieval Art, termos utilizados neste último; na base holandesa Medieval Illuminated Manuscripts, un sistema alfanumérico de clasificación especializado en iconografía denominado Iconclass (e os equivalentes verbais dos códigos alfanuméricos); en Enluminures, un léxico baseado no Thésaurus iconographique de Garnier (1984). ${ }^{8}$ Non temos constancia da utilización sistemática en ningunha das outras ferramentas dun vocabulario concreto, ou dalgún dos tesauros de referencia para describir imaxes artísticas, como o de Garnier, Iconclass ou o TIMEL -específico para obras medievais e accesible en liña (http://cescm.labo.univ-poitiers.fr/ timel/, consultado 10/01/2018)-. ${ }^{9}$

8 Segundo Elizabeth Lalou, na base de datos Initiale, orixe de Enluminures (ver n. 4), para describir as imaxes utilizouse un tesauro baseado no de Garnier, aínda que con termos "en perpetua evolución" (Lalou 2001: 40).

9 Sobre os tesauros e sistemas de clasificación para describir imaxes artísticas, a indexación iconográfica e, en xeral, sobre o acceso ás imaxes polo contido semántico véxase Després-Lonnet (2000b), Layne (2002), Hourihane (2002), Soler i Fabregat (2003) e Cayuela (2014). 
As descricións das miniaturas que analizamos presentan, como mínimo, un campo de contido: a expresión do tema principal da miniatura, asimilable a un título. Polo que se refire á xa citada imaxe do Rei David nos salmos penitenciais (que aquí, para simplificar, estamos denominando David arrepentido) constatamos que a coherencia das bases de datos á hora de consignar este tema varía substancialmente dunhas a outras. A figura -que normalmente se representa como un monarca en actitude de oración ou diálogo coa Divinidade, cun anxo ou con ambos- adoita describirse con enunciados que, ou ben aluden aos seus xestos, ou ben cualifican a súa actitude (facendo referencia ao seu estado de arrepentimento ou penitencia). François Boespflug, na súa análise do Thésaurus des images médiévales, sinalou xa as dificultades que xera a selección dunha expresión axeitada para describir esta imaxe nun tesauro (Boefsplug 1996: 500). En calquera caso, á marxe da idoneidade do termo seleccionado, o determinante desde a óptica da recuperación é que se utilice de forma unívoca. Neste sentido, e tal como se aprecia na táboa que segue (Táboa 2.1), constatamos un bo nivel de coherencia en Medieval Illuminated Manuscripts, Corsair e Mandragore, produto do uso dunha linguaxe controlada para o campo de tema xenérico da miniatura. A consistencia tradúcese no uso dun número reducido de termos nestas tres ferramentas para dar conta dunha mesma realidade: un só código alfanumérico, 71H611 (e o seu equivalente verbal David at prayer), na base de datos holandesa; dúas expresións en Corsair e outras dúas en Mandragore. En Enluminures usáronse máis termos, aínda que predomina o uso de dous deles (David en prière e David priant Dieu). Nos outros recursos -Digital Scriptorium, BLCIM e LUNA-, a incoherencia é maior para describir a figura que nos ocupa, o que revela a ausencia dunha linguaxe controlada para consignar o tema. A base de imaxes da Bodleian Library, LUNA, carece incluso de campo específico para este fin. Só conta cun apartado de descrición con texto libre, onde se mestura, por tanto, a expresión do tema principal e a descrición dos elementos que o representan. Isto tradúcese nunha inconsistencia elevada nesta base de datos para consignar o asunto que nos ocupa.

Ademais do campo de tema, o rexistro iconográfico pode incluír outros campos que describen a ilustración máis en detalle. A partir dos rexistros analizados, constatamos que nalgunhas das bases de datos que ofrecen información detallada tamén se utiliza un vocabulario controlado (os campos de descrición controlada de obxectos, personaxes, elementos naturais, etc., denomínanse en Corsair "Subjects", en Mandragore, "Descripteurs" -Figuras 2.1 e 2.2-). En Medieval Illuminated Manuscripts emprégase o mesmo sistema Iconclass para describir tamén algún elemento concreto das miniaturas. Noutros recursos, esta descrición dos detalles confíase ao texto libre, coa desvantaxe de imposibilitar unha recuperación sistemática: a descrición é moi sucinta en BLCIM (campo 
Táboa 2.1: Descrición do tema de David arrepentido en bases de datos de imaxes de miniaturas (Fonte: elaboración propia)

\begin{tabular}{|c|c|}
\hline Recurso & Expresión do tema \\
\hline Medieval Illuminated Manuscripts & David at prayer \\
\hline Corsair & David in prayer; David communicating with God \\
\hline Mandragore & David pénitent; David priant \\
\hline$B L C I M$ & $\begin{array}{l}\text { (King) David; David in penitence; David penitent; } \\
\text { David in prayer; David kneeling }\end{array}$ \\
\hline Enluminures & $\begin{array}{l}\text { David en prière; David priant; David priant } \\
\text { Dieu; David pénitent; David et l'ange du } \\
\text { châtiment }\end{array}$ \\
\hline Digital Scriptorium & $\begin{array}{l}\text { David penitent; David in penance; David in } \\
\text { penitence; David in prayer; David, King David } \\
\text { kneeling in prayer }\end{array}$ \\
\hline LUNA & $\begin{array}{l}\text { (King) David in prayer; David at prayer; David } \\
\text { prays to God; (King) David praying; (King) David } \\
\text { with harp; King David with his harp; (King) David } \\
\text { raising his hands in prayer; David kneels outside } \\
\text { a castle; David kneeling in prayer; David in } \\
\text { penitence }\end{array}$ \\
\hline
\end{tabular}

"Description"), e tamén en Enluminures, que só a inclúe nalgúns dos rexistros analizados (no campo "Notes"). LUNA, como xa apuntamos, rexistra nun só campo tema xenérico e elementos concretos. Corsair reúne ambas as formas de rexistrar os detalles: o citado campo "Subjects", con termos controlados, e o denominado "Summary", expresado con texto libre. A combinación de ambos aboca nunha descrición moi precisa das miniaturas neste recurso, con moi bos resultados na recuperación.

A falta de control terminolóxico nos campos de contido que describen o tema principal ou os detalles das miniaturas en determinadas bases de datos obriga a realizar buscas demasiado amplas, que se traducen nun exceso de resultados ou "ruído documental": así por exemplo, a localización de todas as imaxes de David arrepentido nalgunhas das ferramentas citadas, sen ter previamente a información que acabamos de ofrecer sobre os termos que se utilizaron nelas, implicaría buscar simplemente "David", coa incómoda consecuencia -dada a rica iconografía do rei bíblico na miniatura- de ter que revisar un gran número de iluminacións para descartar as non pertinentes. 


\section{Instrumentos de carácter monográfico e indexación das imaxes}

As circunstancias que acabamos de describir contribúen a esa complexidade que pode ter, segundo os casos, a procura exhaustiva de imaxes pertinentes para unha investigación. E non hai que olvidar que á esixencia de consultar instrumentos como os que tratamos nestas páxinas -aqueles onde se catalogan as miniaturassúmase a necesidade da procura manual de iluminacións nos facsímiles dixitais de manuscritos dispersos en coleccións de múltiples institucións patrimoniais. ${ }^{10}$ Cómpre salientar, non obstante, a importancia de iniciativas destinadas a facer máis doado este labor, e, en particular, o estándar IIIF (International Image Interoperability Framework, http://iiif.io/, consultado 10/04/2018) desenvolvido e mantido por unha crecente comunidade de bibliotecas e repositorios de todo o mundo e destinado a homoxeneizar a visualización e manipulación de imaxes dixitais, facilitando a confrontación das procedentes de diferentes recursos ou a busca no contido textual asociado ás mesmas. ${ }^{11}$ Contar con ferramentas deste tipo, que chegarán a facer cada vez máis asequible a consulta e interacción coas imaxes accesibles en liña, non impide que, para quen aborde o estudo de códices como os libros de horas - dos que conservamos gran cantidade de exemplareslocalizar, almacenar e organizar ilustracións coa finalidade de cotexalas ou de contextualizar as dun manuscrito determinado, siga a resultar un labor esixente e non exento de dificultades.

10 Dada a gran cantidade de institucións que hoxe ofrecen en liña manuscritos medievais dixitalizados, resulta difícil ofrecer aquí unha selección axeitada das máis relevantes. Para a localización de códices de entidades europeas pódese acudir a portais como Europeana (https:// www.europeana.eu/portal/es, consultado 15/04/18) aínda que é aconsellable facer tamén buscas nos agregadores nacionais (Gallica, Hispana...) ou directamente nas coleccións dixitais das entidades que albergan os manuscritos. Neste sentido, son de grande utilidade recursos que compilan os accesos ás mesmas, como o recollido na web do proxecto Base de datos digital de iconografía medieval, https://www.ucm.es/bdiconografiamedieval/webs-manuscritos (consultado 15/04/2018) ou o elaborado por Siân Echard, da University of British Columbia http://faculty.arts. ubc.ca/sechard/512digms.htm (consultado 15/04/2018).

11 Para unha descrición das súas características técnicas véxase Salarelli (2017). Unha ferramenta salientable especificamente destinada ao traballo con manuscritos medievais e que integra o IIIF é Digital Tools for Manuscript Study, da Universidade de Toronto, financiado pola Andrew W. Mellon Foundation (https://digitaltoolsmss.library.utoronto.ca/, consultado 15/04/2018). 


\subsection{Recursos especializados nun tema}

Cabe considerar, polo tanto, a utilidade da elaboración de instrumentos especializados nos que se aborde a ilustración dun texto, escena ou motivo determinados, ou a iconografía dun personaxe, por exemplo. Nestes traballos é posible reunir e organizar referencias de miniaturas que inclúan a localización das imaxes accesibles e información básica sobre elas dispersa nos recursos e na bibliografía, contribuíndose así a achegar novos materiais que sirvan de apoio á investigación no eido da iluminación de manuscritos.

$\mathrm{Na}$ xestión das referencias de miniaturas reunidas nunha base de datos deste tipo ofrécesenos a ocasión de corrixir as disfuncións detectadas nos recursos institucionais: cabe abordar a ilustración desde unha perspectiva global, pódense uniformar os puntos de acceso, cubrir as lagoas, e, sobre todo, levar o detalle na descrición do contido das imaxes tan lonxe como sexa necesario. Sirva de exemplo, neste sentido, Iconoteca (http://iconoteca.medieval-art.org/, consultado 15/01/2018) o recurso creado por Begoña Cayuela sobre a iconografía medieval hispánica do sacrificio de Isaac -se ben non centrado unicamente en iluminación de manuscritos-. Nel recóllese un amplo repertorio de termos controlados para describir esta escena, o que facilita a recuperación dos máis mínimos detalles das obras indexadas. Cabe subliñar, nesta liña, as posibilidades que un recurso especializado nos ofrece para a elaboración de índices de termos adaptados ás características e á dinámica da ilustración do tema obxecto de estudo.

\subsection{Indexación iconográfica e análise das imaxes}

Unha descrición "a medida”, especialmente minuciosa, ou incluso interpretativa, constituiría, pois, un valor engadido destes instrumentos, libres das inevitables restricións que impón a catalogación de imaxes nos recursos institucionais. Viría complementar así o labor informativo destes últimos e dos vocabularios de carácter máis xenérico que, de ser o caso, neles se utilizan, pensados para dar conta de toda posible realidade representada nun códice iluminado. Despois de todo, a finalidade dos vocabularios e tesauros creados para catalogar obras de arte é a indexación iconográfica, que, tal e como a conciben os creadores do Thésaurus des imaxes médievales, "est un instrument de recherche documentaire et ne saurait être conçue comme une analyse de l'image, ni même comme une véritable description de celle-ci" (GAHOM 1993: 5).

Unha base de datos que compile e organice ilustracións dun texto ou dun tema específico, probablemente imaxes moi semellantes entre si ou que 
abranguen un número reducido de representacións, pode ir máis alá da indexación iconográfica así entendida. A descrición pode incluso ser empregada como método de investigación, de tal xeito que o propio procedemento de creación de termos para organizar a información sirva como medio para a formulación de hipóteses, e, en última instancia, contribúa a abordar a análise das miniaturas. Pensamos nun proceso como o que Marie Després-Lonnet describe cando estuda o funcionamento das bases de datos creadas por investigadores, nas que a alimentación mesma está ligada á práctica investigadora, e faise a medida que se desenvolve o traballo de análise, sen evitar incluso voltas atrás motivadas por hipóteses descartadas (Després-Lonnet 2000a: 50-66).

Hai que ter en conta, por outra parte, que a indexación iconográfica é, en por si, un terreo aberto á reflexión, tamén no ámbito específico da descrición de obras medievais. O Programme OMCI (Ontology of Medieval Christianity in Images), no que están actualmente a colaborar a Jean Paul Getty Foundation e o Institut National d'Histoire de l'Art de Francia, quere propoñer un modelo de descrición que dea conta de conceptos filosóficos e espirituais -en lugar de obxectos ou personaxes- contidos nas imaxes cristiás medievais (Marchesin 2016). A experiencia que implica a realización de traballos como aos que aquí nos referimos, focalizados na ilustración dun tema, motivo ou texto, pode contribuír tamén, desde outro ángulo, a enriquecer o panorama da especulación neste eido, poñendo de relevo as dificultades e achegando as solucións escollidas para a descrición de imaxes específicas.

\section{Conclusión}

As miniaturas medievais dispoñibles en acceso libre en Internet, parte salientable do crecente caudal de imaxes artísticas que ofrecen os recursos institucionais, representan unha riqueza e unha axuda indiscutibles para a investigación. Cómpre ter presente, con todo, que a recuperación eficaz das ilustracións demanda un coñecemento das ferramentas que as conteñen, sobre todo cando se trata de bases de datos de imaxes. A análise que aquí presentamos da descrición de certas ilustracións nestes recursos lévanos a concluír que o proceso pode ser laborioso en determinados casos, particularmente cando se pretende unha recuperación exhaustiva. Esta esixe, ademais, a consulta de facsímiles de manuscritos accesibles en liña, que están a aparecer na rede a un ritmo imparable, o que supón, en moitos casos, dedicar a este labor un esforzo e unha dedicación considerables. De aquí se deriva, ao noso entender, o interese da 
elaboración de instrumentos de carácter monográfico que axuden ás persoas que investigan a sacar máis partido de tan proveitoso material. Este labor, polo esforzo de procura e de descrición das iluminacións que esixe, pode supoñer tamén un estímulo para contribuír á reflexión sobre temas como a indexación iconográfica ou sobre os propios recursos que albergan as ilustracións, algo que debería repercutir, en último termo, en melloras na xestión e difusión das imaxes artísticas.

\section{Referencias bibliográficas}

Angjeli, Anila/Isaac, Antoine (2008): "Web sémantique et interopérabilité des vocabulaires: une expérimentation dans le domaine des enluminures”. En: World Library And Information Congress: 74th IFLA General Conference And Council. [En liña, http://archive. ifla.org/IV/ifla74/papers/129-Angjeli_Isaac-fr.pdf, consultado 15/01/18].

Baschet, Jérôme/Dittmar, Pierre-Olivier (eds.) (2015): Les images dans l'Occident médieval. Turnhout: Brepols.

Baschet, Jérôme/Rigaux, Dominique (2007): “Le médiéviste et les images à l'ère de l'écran global”. En: Actes des congrès de la Société des historiens médiévistes de l'enseignement supérieur public, $38^{e}$ congrès, Île de France, 2007. Etre historien du Moyen Age au XXIe siècle. pp. 259-272. [En liña, https://doi.org/10.3406/shmes.2007.1957, consultado 10/01/2018].

Boefsplug, François (1996): “Le Thésaurus des images médiévales”. En: Revue de synthèse, 417.3-4, pp. 497-501.

Cayuela, Begoña (2014): “La iconografía en la era digital: hacia una heurística para el estudio del contenido de las imágenes medievales". En: Magnificat: cultura i literatura medievals, 1, pp. 1-36. [En liña, https://doi.org/10.7203/MCLM.1.3796, consultado 10/01/2018].

Després-Lonnet, Marie (2000a): Contribution à la conception d'interfaces de consultation de bases de données inconographiques. [Tese de doutoramento.] Université Charles de Gaulle - Lille 3. [En liña, https://tel.archives-ouvertes.fr/tel-01155546v2, consultado 10/01/2018].

Després-Lonnet, Marie (2000b): “Thésaurus iconographiques et modèles culturels”. En: Document numérique, 4.1-2, pp. 153-165. [En liña, https://doi.org/10.3166/dn.4.12.153-165, consultado 10/01/2018].

Drucker, Johanna (2013): “Is There a 'Digital’ Art History?”. En: Visual Resources. An international Journal of Documentation, 29.1-2, pp. 5-13. [En liña, https://doi.org/10.1080 /01973762.2013.761106, consultado 15/04/2018].

GAHOM (Groupe d'Anthropologie Historique de l'Occident Médiéval) (1993): Thésaurus des images médiévales pour la constitution de bases de données iconographiques. Paris: École des hautes études en sciences sociales.

Garnier, François (1984): Thésaurus iconographique: système descriptif des représentations. Paris: Le Léopard d'Or.

Hourihane, Colum (2002): "It Begins with the Cataloguer: Subject Acces to Images and the Cataloguer's Perspective”. En: Baca, Murtha (ed.): An Introduction to Art Image Access: Issues, Tools, Standards, Strategies. Los Angeles: Getty Reseach Institute, pp. 40-66. 
[En liña, http://www.getty.edu/research/publications/electronic_publications/intro_aia/ hourihane.html, consultado 10/01/2018].

Lalou, Élisabeth (2001): “Une base de données sur les manuscrits enluminés des bibliothèques: collaboration entre chercheurs et bibliothécaires". En: BBF 46.4, pp. 38-42. [En liña, http://bbf.enssib.fr/consulter/06-lalou.pdf, consultado 10/01/2018].

Layne, Sara Shatford (2002): "Subject Access to Art Images". En: Baca, Murtha (ed.): An Introduction to Art Image Access: Issues, Tools, Standards, Strategies. Los Angeles: Getty Reseach Institute, pp. 1-19. [En liña, http://www.getty.edu/research/publications/ electronic_publications/intro_aia/layne.html, consultado 10/01/2018].

Marchesin, Isabelle (2016): “Improving Access to Medieval Christian Images". En: The Iris (blog), 7 April 2016. [En liña, http://blogs.getty.edu/iris/improving-access-to-medievalchristian-images/, consultado 10/01/2018].

Rodríguez Ortega, Nuria (2013): “Humanidades digitales, 'Digital Art History' y cultura artística: relaciones y desconexiones”. En: Artnodes, 13, pp. 16-25. [En liña, https://art. ubiquitypress.com/articles/10.7238/a.v0i13.2017/galley/1946/download/, consultado 14/04/2018].

Salarelli, Alberto (2017): “International Interoperability Framework (IIIF): una panoramica”. En: JLIS.it 8.1, pp. 55-66. [En liña, http://dx.doi.org/10.4403/jlis.it-12090 https://www.jlis.it/ article/view/12090, consultado 15/04/2018].

Soler i Fabregat, Ramón (2003): "Recuperació de temes iconogràfics a bases de dades d'imatges artístiques a Internet”. En: Revista de biblioteconomia i documentació, 33, pp. 51-70. [En liña, http://www.raco.cat/index.php/Item/article/viewFile/22588/22422, consultado 15/01/2018]. 